\title{
Natural Segregation of Nucleolar Components in the Course of a Plant Cell Differentiation
}

\author{
Werner W. Franke, Michael F. Trendelenburg, \\ and Ulrich Scheer \\ Department of Cell Biology, Institute of Biology II, \\ University of Freiburg i.Br., D-7800 Freiburg, Schänzlestr. 9-15, \\ Federal Republic of Germany
}

Received November 2, 1972

Summary. Segregation of the nucleolar components is described in the differentiated nucleus of the generative cell in the growing Clivia and Lilium pollen tubes. This finding of a natural nucleolar segregation is discussed against the background of current views of the correlations of nucleolar morphology and transcriptional activity.

\section{Introduction}

Changes in the distribution of the granular and fibrillar parts of the nucleolus are prominent when the nucleolar RNA synthetic activity is repressed by a series of specific drugs. Characteristically, these changes result in a distinct separation of the two structural components, usually as cap or hemisphere formation, referred to as "nucleolar segregation" (Bernhard et al., 1965; Bernhard and Granboulan, 1968; Goldblatt et al., 1970). A similar but naturally occurring nucleolar segregation has been observed in some amphibian cell types such as in embryogenetic stages of the 0-nu mutant of the clawed toad, Xenopus laevis (for review see Hay, 1968), during later stages of erythropoiesis (Tooze and Davies, 1967), and in hepatocytes of adult newts (Reddy and Svoboda, 1972). Other cellular situations which have been interpreted as representing nucleolar segregation are clearly different since they exhibit the pars granulosa merely as a uniform cortex around the fibrillar core [for examples see the micrographs of embryogenetic and oogenetic stages of some amphibian, ophiurid, and crustacean species as were discussed by Giménez-Martín and Stockert (1970) and Reddy and Svoboda (1972); see further the article on the chloragogen cells of the oligochaete, Tubifex tubifex (Djaczenko et al., 1969) and the study of Giménez-Martín and Stockert (1970) on meiotic stages of the onion, Allium cepa]. In addition, we do not consider these cases to be examples of "true" nucleolar segregation since in some of them there is no decrease in nucleolar 
RNA synthesis. The present article shows that true nucleolar segregation occurs during the differentiation of the generative cell of a plant, in apparent concomitance with the progressive inactivation of the nuclear RNA synthesis (Jalouzot, 1969).

\section{Material and Methods}

Pollen tubes of Clivia miniata and Lilium longiflorum were grown on the surface of a $10 \%$ sucrose solution with $10 \mathrm{ppm}$ of boric acid and fixed at room temperature as described previously (Franke et al., 1972). Processing for electron microscopy was identical as in the earlier articles. For sectioning the Epon blocks were longitudinally oriented. Micrographs were taken with a Siemens Elmiskop IA.

\section{Results and Discussion}

The nuclei of the generative and the vegetative cell in growing pollen tubes of the liliiflorae Clivia and the Easter lily, as in many other plants, are markedly different in RNA synthetic rate, stainability and ultramorphology (for references, see e.g., Jalouzot, 1969; Sanger and Jackson, 1971; LaFountain and Mascarenhas, 1972). The nucleus of the vegetative cell is large, highly lobated, characterized by the dispersed state of the chromatin, and very active in RNA synthesis, whereas the nucleus of the generative cell is small, dominated by condensed chromatin distributed in a "chromonema"-like pattern and less active in RNA synthesis. The structural differences of these two nuclear types are illustrated in Fig. 1. In the nucleus of the generative cell one or two small nucleoli (ca. $1.5 \mu \mathrm{m}$ in diameter) can be identified which conspicuously differ from the normal plant nucleoli (Fig. 2). They consist of a very densely packed sphere of pars fibrosa material which is separated from the distinct cap or crescent of the pars granulosa (Fig. 3). This structural appearance of the generative cell nucleoli is typical for what has been defined as "segregated nucleolar components" (see Introduction).

The present report appears to be the first documentation of a typical, naturally occurring segregated nucleolus in a plant cell system. The situation shown by Giménez-Martín and Stockert (1970) represents, in our opinion, a rather normal distribution of nucleolar components with a localization of the pars granulosa in the nucleolar cortex as is

Fig. 1. Low power electron micrograph of a ultrathin section cut longitudinally through a pollen tube of Clivia miniata. The vegetative cell shows a highly lobated nucleus $(V N)$ with evenly dispersed chromatin. The generative nucleus $(G N)$ is located posterior to the vegetative one and is clearly recognizable by its highly condensed chromatin. The intercellular cleft between the vegetative and the generative cell is marked by some arrows. Magnification $\times 5500$ 


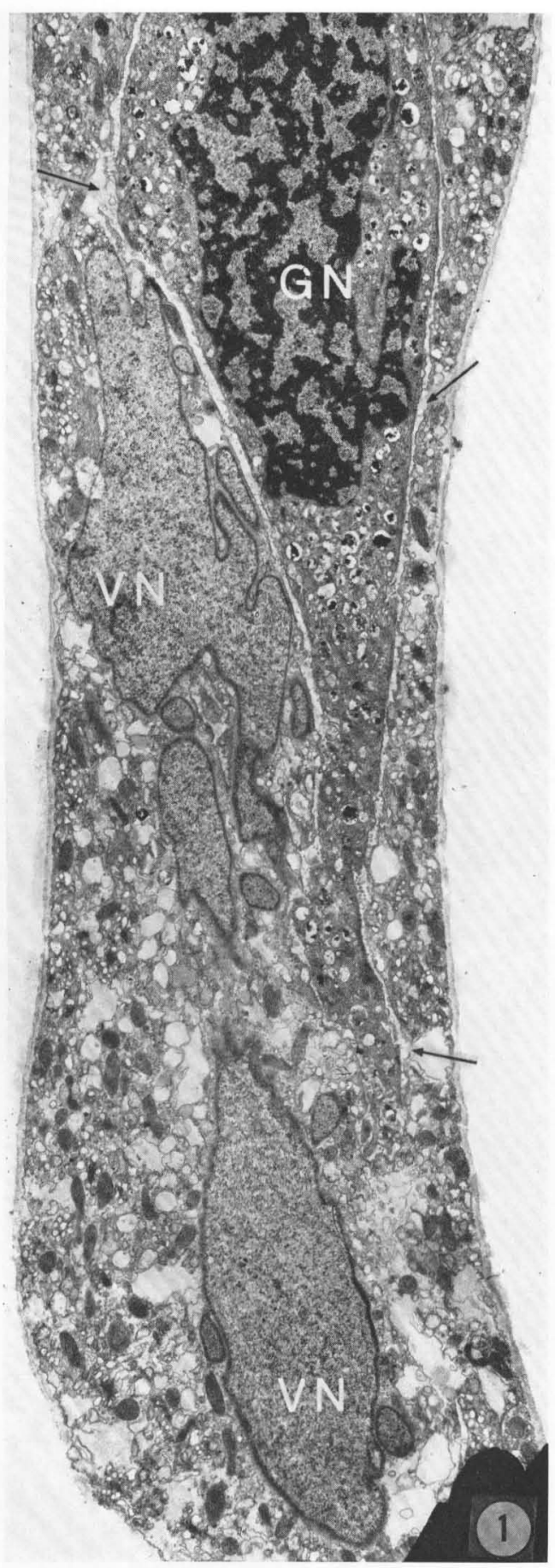

Fig. 1 


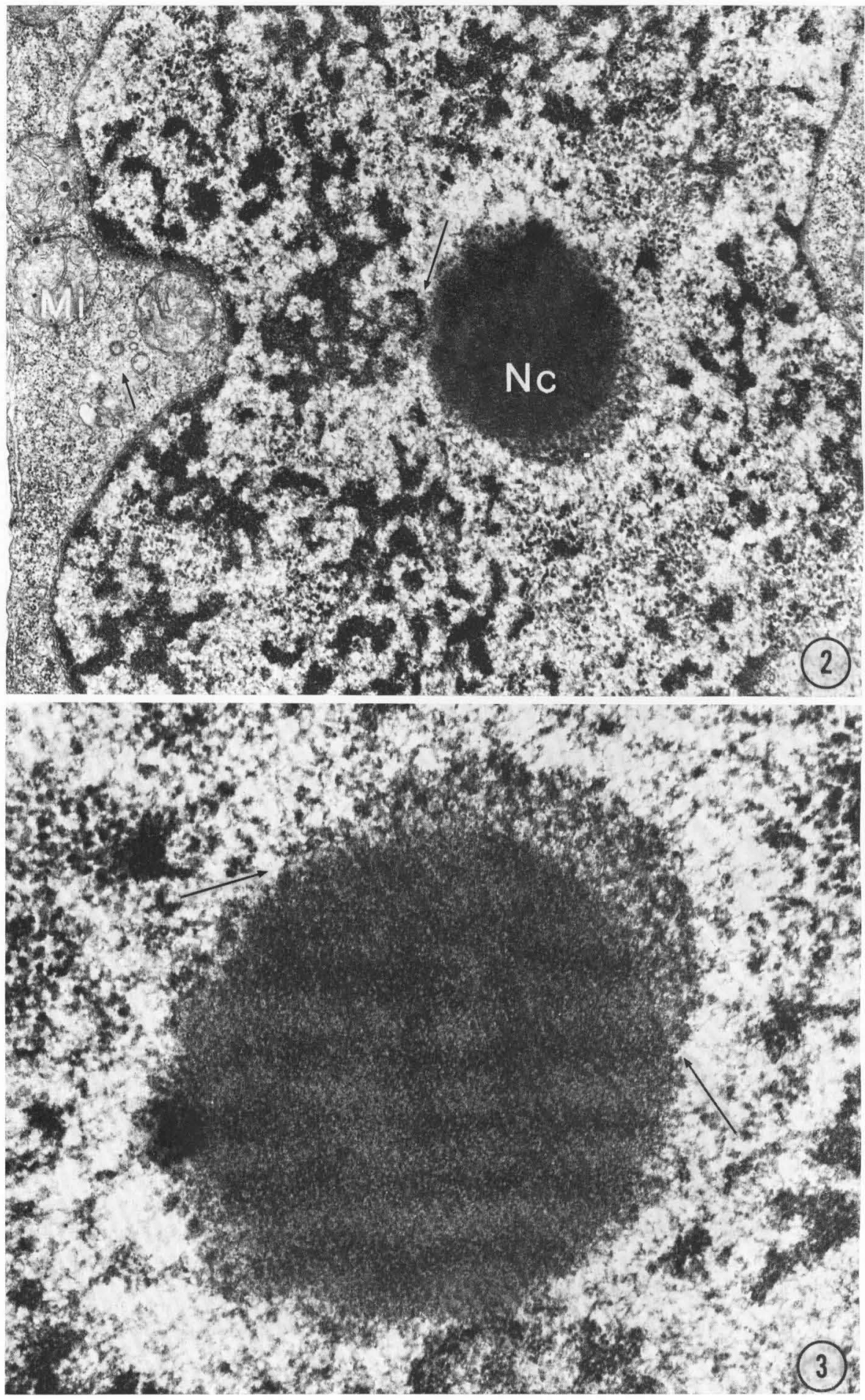


also the case in, e.g., the "classical" nucleolus-type of the amphibian oocyte. In general, such nucleoli with a cortical distribution of pars granulosa material are found in nuclei with a high ribosomal RNA (rRNA) synthetic activity. The occurrence of typical segregated nucleoli, however, seems to be restricted to nuclear stages with a decrease in rRNA synthesis. This holds for the various cases of inhibitions of RNA synthesis (e.g. Bernhard and Granboulan, 1968; Goldblatt et al., 1970; for plant material see Stockert et al., 1970, 1971; Risueño et al., 1972), for the pseudonucleoli of the Xenopus laevis 0-nu mutant (Hay, 1968), for the fused nucleoli in the macronuclei of stationary phase and actinomycin D-treated cultures of the ciliate, Tetrahymena pyriformis, under which conditions "the fibrous material has become pronounced while only a thin rim of granular material still persists" (Satir and Dirksen, 1971), and during later stages of amphibian (Tooze and Davies, 1967) and avian (Zentgraf and Franke, unpublished observations) erythropoiesis. It remains unclear, however, whether the nucleolar segregation reported by Reddy and Svoboda (1972) for some newt hepatocytes also correlates with a decreased rRNA synthesis. In this respect the nucleolar segregation in the nucleus of the generative cell of a pollen tube is another example to demonstrate, first, that this phenomenon is characteristic for a stage of greatly reduced rRNA synthesis (see, e.g., Steffensen, 1966; Jalouzot, 1969; Mascarenhas and Bell, 1970), and second, that this structural change can oceur naturally in the course of a cellular differentiation.

We thank Miss Sigrid Krien and Miss Marianne Winter for careful technical assistance, our colleague Dr. H. Falk for helpful discussions and the Deutsche Forschungsgemeinschaft (SFB 46) for financial support. We are indebted to Miss Patricia Reau (Institut für Biologie III, Universität Freiburg i. Br.) for reading and correcting the manuscript.

Note added in Proof: Recently F. A. L. Clowes and C. De La Torre (Nucleoli in X-rayed meristems. Cytobiologie 6, 318-326, 1972) have demonstrated that $\mathrm{X}$-irradiation of root meristem of Zea mays seedlings produces segregation of the nucleolar components. Another example of a natural "nucleolar segregation" has recently been observed in our laboratory in the secondary nuclei of Acetabularia mediterranea during cyst formation in the caps (W. W. Franke, H. Falk, U. Scheer, and W. Herth, unpublished finding).

Fig. 2. Part of the generative cell nucleus of a Litium longiflorum pollen tube showing a segregated nucleolus $(N c)$. The large arrow points to nucleolus-associated heterochromatin. Small arrow, spiny vesicle; Mi mitochondrion. Magnification $\times 22000$

Fig. 3. The same nucleolus, at higher magnification. The separation of the cap-like pars granulosa (the lateral margins of the cap are marked by the two arrows) from the spherically arranged dense fibrillar component is obvious. Magnification 


\section{References}

Bernhard, W., Frayssinet, C., Lafarge, L., Le Breton, E.: Lésions nucléolaires précoces provoquées par l'aflatoxine dans les cellules hépatiques du rat. C. R. Acad. Sci. (Paris) 261, 1785-1788 (1965).

Bernhard, W., Granboulan, N.: Electron microscopy of the nucleolus in vertebrate cells. In: The nucleus. Ultrastructure in biological systems, ed. by Dalton, A. J., Haguenau, F., vol. 3, p. 81-149. New York-London: Acad. Press 1968.

Djaczenko, W., Grabska, J., Filadoro, F.: Natural segregation of the ribonucleoprotein components of the nucleoli of chloragogen cells in Tubifex. J. Cell Sci. 4, 621-625 (1969).

Franke, W. W., Herth, W., Van Der Woude, W. J., Morré, D. J.: Tubular and filamentous structures in pollen tubes: Possible involvement as guide elements in protoplasmic streaming and vectorial migration of secretory vesicles. Planta (Berl.) 105, 317-341 (1972).

Giménez-Martín, G., Stockert, J. C.: Nucleolar structure during meiotic prophase in Allium cepa anthers. Z. Zellforsch. 107, 551-563 (1970).

Goldblatt, P. J., Verbin, R. S., Sullivan, R. J.: Induction of nucleolar segregation by actinomycin $\mathrm{D}$ following inhibition of protein synthesis with cycloheximide. Exp. Cell Res. 63, 117-123 (1970).

Hay, E. D.: Structure and function of the nucleolus in developing cells. In: The nucleus. Ultrastructure in biological systems, ed. by Dalton, A. J., Haguenau, F., vol. 3, p. 1-79. New York-London: Acad. Press 1968.

Jalouzot, R.: Différenciation nucléaire et cytoplasmique du grain du pollen de Lilium candidum. Exp. Cell Res. 55, 1-8 (1969).

La Fountain, K. L., Mascarenhas, J. P.: Isolation of vegetative and generative nuclei from pollen tubes. Exp. Cell Res. 73, 233-236 (1972).

Mascarenhas, J. P., Bell, E.: RNA synthesis during development of the male gametophyte of Tradescantia. Develop. Biol. 21, 475-490 (1970).

Reddy, J. K., Svoboda, D. J.: Natural segregation of nucleolar components of liver cells in newts. J. Ultrastruct. Res. 38, 608-613 (1972).

Risueño, M. C., Fernández-Gómez, M. E., de la Torre, C., Giménez-Martín, G.: Effect of ethidium bromide on the fine structure of the nucleolus in plant cells. J. Ultrastruct. Res. 39, 163-172 (1972).

Sanger, J. M., Jackson, W. T.: Fine structure study of pollen development in Haemanthus katherinae Baker. II. and III. J. Cell Sci. 8, 303-329 (1971).

Satir, B., Dirksen, E. R.: Nucleolar aging in Tetrahymena during the cultural growth cycle. J. Cell Biol. 48, 143-154 (1971).

Steffensen, D. M.: Synthesis of ribosomal RNA during growth and division in Lilium. Exp. Cell Res. 44, 1-12 (1966).

Stockert, J. C., Colman, O. D., Risueño, M. C., Fernández-Gómez, M. E.: Nucleolar segregation by cold 2-4 dinitrophenol or anoxia in plant cells. Cytologia (Tokyo) 36, 499-503 (1971).

Stockert, J. C., Fernández-Gómez, M. E., Sogo, J. M., López-Sáez, J. F. : Nucleolar segregation by adenosine 3 '-deoxyriboside (cordycepin) in root tip cells of Allium cepa. Ezp. Cell Res. 59, 85-89 (1970).

Tooze, J., Davies, H. G.: Light and electron microscope studies on the spleen of the newt Triturus cristatus: The fine structure of erythropoietic cells. J. Cell Sci. 2, 617-640 (1967). 